\title{
Human Suction Blister Interstitial Fluid Prevents Metal lon-dependent Oxidation of Low Density Lipoprotein by Macrophages and in Cell-free Systems
}

\author{
Alya J. Dabbagh and Balz Frei
}

Whitaker Cardiovascular Institute, Boston University School of Medicine, Boston, Massachusetts 02118

\begin{abstract}
LDL in the circulation is well protected against oxidation by the highly efficient antioxidant defense mechanisms of human plasma. LDL oxidation contributing to atherosclerosis, therefore, has been hypothesized to take place in the interstitial fluid of the arterial wall. We investigated the antioxidant composition and the capacity to inhibit LDL oxidation of human suction blister interstitial fluid (SBIF), a suitable representative of interstitial fluid. We found that the concentrations in SBIF of the aqueous small-molecule antioxidants ascorbate and urate were, respectively, significantly higher $(P<0.05)$ and identical to plasma concentrations. In contrast, lipoprotein-associated lipids and lipidsoluble antioxidants ( $\alpha$-tocopherol, ubiquinol-10, lycopene, and $\beta$-carotene) were present at only 8-23\% of the concentrations in plasma. No lipid hydroperoxides could be detected $(<5 \mathrm{nM})$ in either fluid. The capacity of serum and SBIF to protect LDL from oxidation was investigated in three metal ion-dependent systems: copper, iron, and murine macrophages in Ham's F-10 medium. In all three systems, addition of $\geq 6 \%$ ( vol/vol) of either serum or SBIF inhibited LDL oxidation by $>90 \%$. The concentration that inhibited macrophage-mediated LDL oxidation by $50 \%$ was as low as $0.3 \%$ serum and $0.7 \%$ SBIF. The enzymatic or physical removal of ascorbate or urate and other low molecular weight components did not affect the ability of either fluid to prevent LDL oxidation, and the high molecular weight fraction was as protective as whole serum or SBIF. These data demonstrate that both serum and SBIF very effectively protect LDL from metal ion-dependent oxidation, most probably because of a cumulative metal-binding effect of several proteins. Our data suggest that LDL in the interstitial fluid of the arterial wall is very unlikely to get modified by metal ion-mediated oxidation. (J. Clin. Invest. 1995. 96:1958-1966.) Key words: atherosclerosis • free radicals • antioxidants $\bullet$ metal ions $\bullet$ low density lipoprotein
\end{abstract}

\section{Introduction}

Atherogenesis is a complex process in which oxidation of LDL is thought to play a critical causal role $(1,2)$. Oxidized LDL

Address correspondence to Balz Frei, Whitaker Cardiovascular Institute, Boston University School of Medicine, 80 East Concord Street, W-601, Boston, MA 02118. Phone: 617-638-4896; FAX: 617-638-4066.

Received for publication 8 September 1994 and accepted in revised form 16 June 1995.

\section{J. Clin. Invest}

(C) The American Society for Clinical Investigation, Inc. 0021-9738/95/10/1958/09 \$2.00 Volume 96, October 1995, 1958-1966 contributes to the atherosclerotic process via several mechanisms, including its uptake by macrophages leading to cholesterylester enrichment and foam cell formation (3); chemotactic activity for circulating monocytes $(1,2)$; inhibition of the motility of tissue macrophages, thus leading to their "trapping" within the intima (1); and inhibition of endothelium-dependent vasodilation $(4,5)$. Several lines of evidence support the hypothesis that LDL oxidation occurs in the artery wall in vivo. First, LDL can be oxidized, under appropriate in vitro conditions, by cells present in the atherosclerotic arterial wall (macrophages, smooth muscle, and endothelial cells) (6-9). Second, lesion LDL demonstrates increased electrophoretic mobility and fragmentation of apolipoprotein $\mathrm{B}(10,11)$, which are characteristic features of oxidized LDL, even though the extent of in vivo oxidation of LDL is unclear (12). Third, lesion LDL also reacts with antibodies specific for proteins modified by malondialdehyde and 4-hydroxynonenal, byproducts of lipid peroxidation (13).

Most of the evidence for the presence of oxidized LDL in vivo is confined to atherosclerotic tissue. Although there are reports of a small oxysterol-enriched subfraction of LDL in plasma that is more negatively charged than native LDL and exhibits cytotoxicity towards endothelial cells in culture (14, 15 ), the formation of this subfraction is not likely to occur in plasma. This is because plasma has highly efficient antioxidant defense mechanisms to suppress lipid peroxidation (16). In addition, the absence of detectable amounts of lipid hydroperoxides in fresh human plasma (17) and the strong inhibitory effect of serum on LDL oxidation in vitro (9) are indicative of the potent antioxidant capacity of plasma. LDL oxidation in vivo, therefore, is thought to take place in the interstitial space of the arterial wall $(1,2)$, where LDL may be shielded from the various antioxidants present in plasma. To date there are no studies investigating the antioxidant capacity of interstitial fluid (IF) ${ }^{1}$ and how this fluid may affect LDL oxidation.

The composition of IF is influenced by several factors such as the permeability of the capillary endothelium, the physicochemical properties of the matrix within the interstitial space, and modification, addition, or removal of components by peripheral cell metabolism (18). Therefore, the composition of IF will vary according to the location and the method of collection. Of particular interest with respect to atherosclerosis is the aortic intimal IF. This fluid has been obtained from human autopsy and animal samples of the aortic wall by using small pieces of filter paper $(19,20)$. However, it is not possible to obtain aortic intimal IF in volumes sufficient to perform

1. Abbreviations used in this paper: $\mathrm{IC}_{50}$, concentrations required to inhibit LDL oxidation by $50 \%$; IF, interstitial fluid; NTA, nitrilotriacetic acid; REM, relative electrophoretic mobility; SBIF, suction blister interstitial fluid; TBARS, thiobarbituric acid-reactive substances. 
antioxidant analysis and LDL oxidation experiments as those reported in the present study. This important limitation does not exist for human suction blister interstitial fluid (SBIF) which is a water-clear, acellular fluid collected from several skin blisters raised by mild suction $(250-300 \mathrm{mmHg})$ over several hours $(21-23)$. Collection of SBIF is noninflammatory and is not associated with increased vascular permeability (23), factors that could lead to oxidation and altered fluid composition. The concentration of proteins in human SBIF in general is inversely proportional to their molecular weight, e.g., the concentrations of albumin $(\mathrm{mol} \mathrm{wt} \simeq 67,000)$ and $\mathrm{LDL}(\mathrm{mol} \mathrm{wt} \simeq 2,300,000)$ in SBIF are $~ 30$ and $15 \%$, respectively, of those in serum (21, $23)$. SBIF differs from aortic intimal IF in that LDL levels are much higher in the latter $(200 \%$ of serum levels $)(19,20,24)$. This is thought to be due to LDL accumulating in the arteria intima by binding to components of the extracellular matrix, i.e., proteoglycans, elastin, and collagen (25). However, levels of high density lipoprotein and albumin are comparable between aortic intimal and SBIF (19-21, 23). Human SBIF has been used successfully for the investigation of lipoprotein metabolism in IF (21), and several workers have concluded that SBIF is a suitable representative of $\operatorname{IF}(23,26)$.

The aim of this study was to investigate the hypothesis that LDL is more susceptible to metal ion-dependent oxidation in IF than in plasma. We have, therefore, measured the levels of lipid hydroperoxides and selected water- and lipid-soluble antioxidants in human SBIF and plasma obtained from the same subject. We then compared the effects of SBIF with those of serum on in vitro LDL oxidation in three metal ion-dependent systems, namely, copper, iron, and murine macrophages.

\section{Methods}

Materials. Sodium heparin Vacutainers (for plasma preparation), Vacutainers without addition (for serum preparation), needles, and plastic syringes were purchased from Becton Dickinson (Rutherford, NJ). Acrodisc LC13 syringe filters were from Gelman Sciences Inc. (Ann Arbor, MI), Centrifree micropartition system from Amicon Inc. (Beverly, MA), HPLC columns from Supelco Inc. (Bellefonte, PA), and Lipo gels for agarose gel electrophoresis of LDL from Beckman Instruments Inc. (Brea, CA). The suction blister device consisting of a handheld vacuum pump connected to a suction cup was obtained from Itka Oy (Espoo, Finland). Chelex-100 resin was purchased from Bio-Rad Laboratories (Richmond, CA), and 15-hydroperoxy-eicosatetraen-1-oic acid from Cayman Chemical Co., Inc. (Ann Arbor, MI). Organic solvents (HPLC grade) were purchased from Fisher Scientific Co. (Fairlawn, NJ). Human transferrins at three levels of iron saturation were obtained from Boehringer Mannheim Biochemicals (Indianapolis, IN). Tissue culture media were obtained from Gibco BRL (Gaithersburg, MD). HSA (essentially fatty acid free) and all other chemicals were obtained from Sigma Chemical Co. (St. Louis, MO). $\mathrm{CuSO}_{4} \cdot 5 \mathrm{H}_{2} \mathrm{O}$ was prepared in Chelex-treated water adjusted to $\mathrm{pH} 3.0$ and was diluted from a $10-\mathrm{mM}$ stock solution just before use in experiments. Iron was complexed to nitrilotriacetic acid (NTA) as described by Teichmann and Stremmel (27). A stock solution of ferric chloride was prepared in the presence of a fourfold molar excess of NTA in $20 \mathrm{mM}$ Hepes-Tris buffer, $\mathrm{pH} 6.0$, containing $100 \mathrm{mM} \mathrm{HCl}$, and subsequently titrated to neutral $\mathrm{pH}$ with $10 \mathrm{mM} \mathrm{NaOH}$. Standard culture medium was Ham's F10 medium containing $100 \mathrm{IU} / \mathrm{ml}$ penicillin and $100 \mu \mathrm{g} / \mathrm{ml}$ streptomycin (Gibco BRL).

SBIF. This fluid was obtained by dermo-epidermal separation by application of suction to normal human skin according to the method of Kiistala (22). Briefly, a suction cup containing a plastic adaptor plate with five holes (6-mm diameter) was applied to the forearm of three healthy volunteers, one female and two males, ages 32-36 yr, and mild suction of $250-300 \mathrm{mmHg}$ was applied for 3-4 h until blisters developed. The fluid in the blisters was collected with a 23G 3/4 needle into a 1.0-ml plastic syringe, transferred to an Eppendorf tube, and kept on ice, under $\mathrm{N}_{2}$, and in the dark until analyzed or used in experiments (within $2 \mathrm{~h}$ ). The total volume of fluid collected from the five blisters ranged from 80-120 $\mu \mathrm{l}$. Shortly before the SBIF was collected, a blood sample was obtained from the same donor and plasma or serum was prepared for comparison with SBIF.

$L D L$ isolation. After an overnight fast, blood from a healthy normolipidemic volunteer was collected in a Vacutainer tube ( 286 USP sodium heparin $/ 15 \mathrm{ml} \mathrm{blood}$ ) and centrifuged $\left(500 \mathrm{~g}\right.$ for $20 \mathrm{~min}$ at $7^{\circ} \mathrm{C}$ ) to obtain plasma. LDL was isolated from fresh plasma by single vertical spin discontinuous density gradient ultracentrifugation (28). Plasma density was adjusted to $1.21 \mathrm{~g} / \mathrm{ml}$ with solid $\mathrm{KBr}(0.3265 \mathrm{~g} / \mathrm{ml}$ plasma $)$, and a discontinuous $\mathrm{NaCl} / \mathrm{KBr}$ gradient was established in centrifuge tubes by layering the density-adjusted plasma $(1.5 \mathrm{ml})$ under $0.154 \mathrm{M}$ $\mathrm{NaCl}(3.5 \mathrm{ml})$. The samples were centrifuged at $80,000 \mathrm{rpm}(443,000$ $g$ ) for $45 \mathrm{~min}$ at $7^{\circ} \mathrm{C}$ in a rotor (Near Vertical Tube 90 ; L8-80M ultracentrifuge; Beckman Instruments) using slow acceleration and deceleration modes (mode 3). After centrifugation, LDL was observed as a yellow band in the upper middle portion of the tubes and was removed by puncturing the tube wall with a hypodermic needle and withdrawing the LDL into a syringe. Adventitious metal ions were removed from the isolated LDL by adding Chelex-100 resin $(\sim 0.1 \mathrm{~g} / \mathrm{ml})$ with gentle mixing. The resin was removed by centrifugation $(500 \mathrm{~g}$ for $2 \mathrm{~min}$ at $\left.7^{\circ} \mathrm{C}\right)$ and the supernatant containing the LDL was filtered $(0.2-\mu \mathrm{m}$ Acrodisc filter). $\mathrm{KBr}$ and possible low molecular weight contaminants were removed from LDL by passage through a Sephadex G-25-300 column (see below). LDL protein was determined by a modification (29) of the Lowry method (30).

Measurement of lipids, lipid hydroperoxides, and antioxidants. Lipid hydroperoxides in plasma and SBIF were quantified using an HPLC method with chemiluminescence detection $(17,31)$ and 15-hydroperoxy-eicosatetraen-1-oic acid as a standard. The same method with detection at $210 \mathrm{~nm}$ was used to quantify free and esterified cholesterol and triglycerides (17). Water- and lipid-soluble antioxidant concentrations were determined by HPLC with electrochemical detection $(32,33)$.

Thiobarbituric acid-reactive substances (TBARS). TBARS, which exhibit an absorbance maximum at $532 \mathrm{~nm}$, were measured in fresh plasma samples according to the methods of Halliwell and Gutteridge $(34,35)$.

Relative electrophoretic mobility (REM) of $L D L$. Increased anodic electrophoretic mobility of LDL on agarose gels was used to assess oxidative modification (36). Electrophoresis was carried out at $100 \mathrm{~V}$ for $30 \mathrm{~min}$ in $0.5 \%$ agarose gels with $0.05 \mathrm{M}$ barbital buffer, $\mathrm{pH} 8.6$, (Beckman Paragon system; Beckman Instruments). The gels were fixed and stained with Sudan black B stain and destained according to the manufacturer's instruction. The distance $(\mathrm{mm})$ of the band for native LDL (LDL which was kept at $4^{\circ} \mathrm{C}$ under $\mathrm{N}_{2}$ ) from the origin was defined as 1, and REM of other LDL bands was expressed as multiples of the mobility of native LDL.

Treatment of plasma and $L D L$ by gel filtration. To remove low molecular weight components (such as $\mathrm{KBr}$ from $\mathrm{LDL}$ and ascorbate and urate from serum), LDL or serum were subjected to gel filtration. For each Sephadex G-25-300 column to be prepared, $10 \mathrm{ml}$ of a suspension containing $6.25 \mathrm{~g}$ of filtered moist resin in $5 \mathrm{ml}$ of $10 \mathrm{mM}$ PBS, $\mathrm{pH} 7.4$, was transferred into a polypropylene Econo-Column (Bio-Rad). The column was centrifuged in a swinging bucket rotor for $10 \mathrm{~min}$ at $600 \mathrm{~g}$ and $7^{\circ} \mathrm{C}$. To equilibrate the resin, $2.5 \mathrm{ml}$ of PBS was added, and the column was spun again for $15 \mathrm{~min}$. This step was repeated once, and then $0.75 \mathrm{ml}$ of serum or LDL solution was applied to the dry resin. The column was centrifuged for $15 \mathrm{~min}$ and the eluate collected.

Isolation of macrophages. Resident peritoneal macrophages were harvested by peritoneal lavage of female Swiss Webster mice (8-12 wk of age, weighing 25-35 g, from Charles River Laboratories, Wilmington, MA). Briefly, the mice were killed in a $\mathrm{CO}_{2}$ chamber and $10 \mathrm{ml}$ of ice cold DME containing $50 \mu \mathrm{g}$ of gentamicin/ml and $10 \%$ ( $\mathrm{vol} /$ 
Table I. Concentration of Water- and Lipid-soluble Antioxidants, Lipids, and Lipid Hydroperoxides in Human SBIF and Plasma

\begin{tabular}{|c|c|c|c|c|}
\hline \multirow[b]{2}{*}{ Compound } & \multicolumn{3}{|c|}{ Mean \pm SD } & \multirow[b]{2}{*}{$P$-value } \\
\hline & Interstitial fluid & Plasma & Percent & \\
\hline \multicolumn{5}{|l|}{ Antioxidants $(\mu \mathrm{M})$} \\
\hline Reduced ascorbate (3) & $86.6 \pm 6.0$ & $73.1 \pm 3.9$ & $118.7 \pm 9.6$ & $<0.05$ \\
\hline Total ascorbate (3) & $96.4 \pm 10.1$ & $80.4 \pm 11.0$ & $120.3 \pm 7.0$ & NS \\
\hline Percent reduced (3) & $90.1 \pm 5.0$ & $90.9 \pm 7.9$ & - & NS \\
\hline Urate & $238 \pm 14$ & $246 \pm 13$ & $97.0 \pm 10.0$ & NS \\
\hline$\alpha$-Tocopherol & $5.4 \pm 0.7$ & $26.8 \pm 2.5$ & $20.3 \pm 2.4$ & $<0.001$ \\
\hline Ubiquinol-10 (3) & $0.09 \pm 0.02$ & $1.08 \pm 0.19$ & $8.3 \pm 1.4$ & $<0.001$ \\
\hline Total ubiquinone-10 (3) & $0.11 \pm 0.04$ & $1.22 \pm 0.13$ & $9.3 \pm 2.0$ & $<0.001$ \\
\hline Percent reduced (3) & $76.8 \pm 20.6$ & $88.3 \pm 6.4$ & - & NS \\
\hline Lycopene & $0.018 \pm 0.003$ & $0.197 \pm 0.033$ & $9.3 \pm 1.7$ & $<0.001$ \\
\hline$\beta$-Carotene & $0.056 \pm 0.007$ & $0.482 \pm 0.061$ & $11.9 \pm 1.6$ & $<0.001$ \\
\hline \multicolumn{5}{|l|}{ Lipids (mM) } \\
\hline Free cholesterol & $0.27 \pm 0.03$ & $1.22 \pm 0.14$ & $22.6 \pm 2.5$ & $<0.001$ \\
\hline Cholesterylesters & $0.48 \pm 0.08$ & $3.17 \pm 0.23$ & $15.6 \pm 3.3$ & $<0.001$ \\
\hline Triglycerides (3) & $0.08 \pm 0.03$ & $0.62 \pm 0.10$ & $13.1 \pm 5.2$ & $<0.001$ \\
\hline Lipid hydroperoxides & n.d. $(<5 \mathrm{nM})$ & n.d. $(<5 \mathrm{nM})$ & & \\
\hline
\end{tabular}

Data shown represent the mean \pm SD of four SBIF and plasma samples obtained from the same healthy donor on different occasions, unless otherwise indicated (numbers in parentheses). Percent indicates the relative concentration in SBIF compared to plasma, i.e., $\%=[\mathrm{SBIF}] /[\mathrm{plasma}] \times 100$; n.d., not detectable; $N S$, not significant $(P>0.05)$.

vol) heat-inactivated FBS (Gibco BRL) was injected into the peritoneal cavity. The medium containing the macrophages was removed and the cells were spun $(300 \mathrm{~g}, 10 \mathrm{~min})$ and resuspended in DME. The cells were washed in DME, counted, and plated in 22.6-mm diameter wells in 12-well cluster plates (Costar Corp., Cambridge, MA), at $1.5 \times 10^{6}$ cells per well. The cells were incubated for $2 \mathrm{~h}$ in a humidified incubator $\left(37^{\circ} \mathrm{C}, 5 \% \mathrm{CO}_{2}\right)$, and then washed four times with Ham's F-10 medium to remove any nonadherent cells (erythrocytes and lymphocytes). The cultures were used immediately for LDL oxidation experiments.

$L D L$ oxidation. In the copper system, freshly isolated LDL $(100 \mu \mathrm{g}$ protein/ml) was incubated with $5 \mu \mathrm{M} \mathrm{CuSO}_{4}$ in Ham's F-10 medium in the presence or absence of 10 or $1 \%(\mathrm{vol} / \mathrm{vol})$ of SBIF or serum. After $24 \mathrm{~h}$ of incubation at $37^{\circ} \mathrm{C}$, REM of LDL was determined on agarose gels and lipid peroxidation was assessed by measurement of TBARS.

In the macrophage and iron systems, freshly isolated LDL, which had been passed through a gel filtration column to remove $\mathrm{KBr}$, was added at a concentration of $100 \mu \mathrm{g}$ of protein $/ \mathrm{ml}$ to macrophages or cell-free wells in $0.5 \mathrm{ml}$ of Ham's F-10 medium containing $10 \mu \mathrm{M}$ ferric iron complexed to NTA in a $1: 4$ ratio (Fe-NTA, see above). Serum or SBIF, which had been heated to $56^{\circ} \mathrm{C}$ for $30 \mathrm{~min}$ to inactivate complement, was added at $6,1,0.5$, or $0.25 \%$ ( vol/vol). After $24 \mathrm{~h}$ of incubation (in a humidified incubator; $37^{\circ} \mathrm{C}, 5 \% \mathrm{CO}_{2}$ ), the medium was centrifuged $(1,500 \mathrm{~g}$ for $10 \mathrm{~min})$ to remove detached cells, and REM and TBARS of LDL were examined as above.

To investigate the role of the aqueous low molecular weight antioxidants urate and ascorbate in protecting LDL from oxidation, heat-inactivated serum and SBIF were incubated at $25^{\circ} \mathrm{C}$ for $40 \mathrm{~min}$ with ascorbate oxidase $(30 \mathrm{U} / \mathrm{ml})$, uricase type $\mathrm{I}(0.2 \mathrm{U} / \mathrm{ml})$, or without addition (control). Alternatively, serum was passed through a Sephadex G-25300 column to remove low molecular weight components including both urate and ascorbate. Finally, serum was separated into a low molecular weight filtrate fraction and a high molecular weight $(>30,000 \mathrm{D})$ retenate fraction in the Centrifree micropartition system (Amicon) by centrifugation at $1,000 \mathrm{~g}$ for $3 \mathrm{~h}$ at $4^{\circ} \mathrm{C}$. The treated samples were then tested for their ability to protect LDL from oxidation in the above incubation systems.

We also investigated the role of two plasma proteins (albumin and transferrin) in iron- and copper-mediated LDL oxidation in Ham's F10 medium. HSA, apo-transferrin, transferrin saturated with iron similar to normal plasma levels $(20-30 \%)$ and holo-transferrin $(100 \%$ iron saturated) were made up in PBS solutions at average plasma concentrations $(50 \mathrm{~g} /$ liter albumin and $3 \mathrm{~g} /$ liter transferrin) and were incubated with Chelex-100 beads $(\sim 0.1 \mathrm{~g} / \mathrm{ml})$ for $3 \mathrm{~h}$ to remove nonspecifically bound adventitious metal ions. LDL was oxidized as described above in the iron and copper systems in the presence or absence of $6 \%$ serum, albumin, apo-transferrin, transferrin, holo-transferrin, or a combination of albumin and transferrin. After $24 \mathrm{~h}$ of incubation at $37^{\circ} \mathrm{C}, \mathrm{REM}$ of LDL was determined on agarose gels.

Albumin measurements. Albumin concentrations in plasma and SBIF were measured spectrophotometrically using the albumin reagent bromocresol green assay as specified by Sigma (Procedure No. 631).

Statistical methods. Statistical significance was determined by using the unpaired Student's $t$ test. Statistical significance was accepted at the $P<0.05$ level.

\section{Results}

The antioxidant and lipid profiles of SBIF compared to paired plasma samples from the same donor are shown in Table I. The concentration of the water-soluble antioxidant ascorbate (reduced form) was significantly higher $(P<0.05)$ in SBIF than in plasma, and urate was present at about the same concentration in both fluids. In contrast, the lipid-soluble antioxidants ubiquinol-10, $\alpha$-tocopherol, $\beta$-carotene, and lycopene were present at considerably lower levels in SBIF (8-20\%) compared to plasma. These results were to be expected as the lipidsoluble antioxidants are associated with large lipoproteins (mainly LDL) that cannot freely diffuse from the blood plasma into the interstitium $(18,23)$. This is also reflected in the levels of lipoprotein-associated lipids, which were substantially lower in SBIF than in plasma (Table I). Triglycerides were present at the lowest relative concentration ( $13 \%$ of plasma), since they are mainly associated with large very low density lipoproteins. 

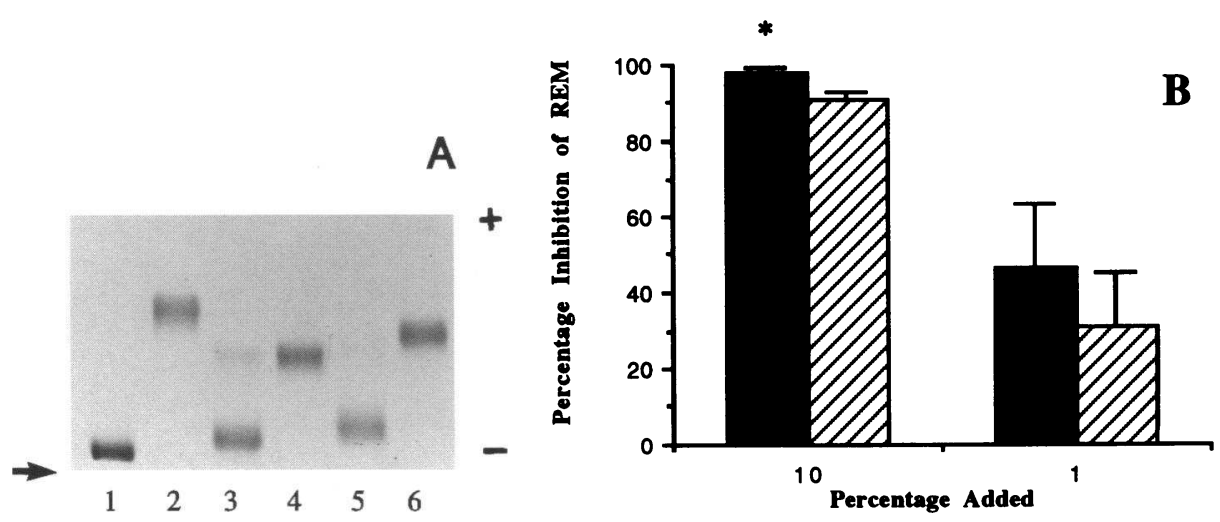

Figure 1. Inhibition of copper-mediated LDL oxidation by serum and SBIF. LDL (protein $=100 \mu \mathrm{g} / \mathrm{ml}$ ) was incubated with $5 \mu \mathrm{M} \mathrm{CuSO}_{4}$ in Ham's F-10 medium in the absence (control) or presence of $10 \%(\mathrm{vol} / \mathrm{vol})$ or $1 \%$ serum or SBIF. After $24 \mathrm{~h}$ of incubation at $37^{\circ} \mathrm{C}$, the electrophoretic mobility of LDL was determined on an agarose gel $(A)$. Lane 1 : native LDL; lane 2: LDL incubated with $\mathrm{Cu}^{2+}$ (control); lanes 3-4: LDL incubated with $\mathrm{Cu}^{2+}$ plus 10 and $1 \%$ serum, respectively; lanes 5-6: LDL incubated with $\mathrm{Cu}^{2+}$ plus 10 and $1 \%$ SBIF, respectively; the arrow indicates the point of origin. The faint band in lane 3 above the LDL band represents high density lipoprotein, which is present in added serum. $B$ shows the percent inhibition by 10 and $1 \%$ serum (solid columns) and SBIF (hatched columns) of the REM of LDL. The data were derived from $A$, with $0 \%$ inhibition corresponding to control LDL incubated with copper alone (lane 2 of $A$ ), and $100 \%$ inhibition corresponding to native LDL (lane 1 of $A$ ). Data shown in $B$ represent the mean \pm standard error of three experiments using serum or SBIF obtained from the same healthy donor on different occasions. ${ }^{*} P<0.05$, SBIF vs. serum.

We also compared the redox status of SBIF with that of plasma by measuring the ratio of reduced ascorbate/total ascorbate (as indicator of aqueous phase redox status) and ubiquinol$10 /$ total ubiquinone-10 (as indicator of lipoprotein redox status). Ascorbate and ubiquinol-10 were chosen because they form the first line of antioxidant defense in plasma and LDL, respectively $(16,32,33)$, and therefore, the redox status of these compounds is very sensitive to oxidizing conditions. Ascorbate redox status was identical in plasma and SBIF, i.e., $90 \%$ reduced, and ubiquinone-10 was slightly but not significantly less reduced in SBIF compared to plasma (Table I). In addition, no lipid hydroperoxides could be detected in either fluid by a sensitive and selective HPLC/chemiluminescence assay with a detection limit of $5 \mathrm{nM}(17,31)$.

We also measured the SBIF/serum concentration ratio of albumin in three different subjects, and they were found to be $0.26,0.27$, and 0.29 , i.e., $0.27 \pm 0.02($ mean $\pm S D)$. This value is in excellent agreement with the published value of $0.29 \pm 0.04$ $(n=6)$ (23) and is also in keeping with the observations that the SBIF/plasma concentration ratio of proteins is dependent on molecular weight and follows mainly the law of diffusion (23). Hence, the sieve function of the capillary basement membrane remained intact during the formation of the suction blisters. Taken together, the above data indicate that $(a)$ the suction technique does not cause oxidation artifacts; $(b)$ SBIF is an ultrafiltrate of plasma; and (c) SBIF, like plasma, represents a strongly reducing environment.

After the characterization of the antioxidants and the redox status of SBIF, we sought to compare SBIF with serum in their ability to affect metal ion-dependent LDL oxidation in several established in vitro systems, namely, copper, iron, or macrophages in Ham's F-10 medium. In the copper system ( $5 \mu \mathrm{M}$ $\mathrm{CuSO}_{4}$ ), the addition of $10 \%$ ( $\mathrm{vol} / \mathrm{vol}$ ) of either serum or SBIF led to more than $90 \%$ inhibition $(P<0.001)$ of LDL oxidation as assessed by agarose gel electrophoresis (Fig. $1 A$ ) and expressed as inhibition of REM (Fig. $1 B$ ). Assessment of lipid peroxidation by the TBARS assay showed a similar, though less marked, trend with $95.5 \pm 0.7$ and $65.0 \pm 28.3 \%$ inhibition of TBARS formation by $10 \%$ serum and SBIF, respectively. The addition of $1 \%$ of either serum or SBIF to the incubation of LDL with copper led to a 46 and $31 \%$ inhibition of LDL oxidation, respectively, as assessed by gel electrophoresis (Fig. 1). At both 10 and $1 \%$ concentrations, SBIF was somewhat less effective than serum at inhibiting copper-mediated LDL oxidation, but this difference was statistically significant only at $10 \%(P<0.05)$.

While the results in Fig. 1 were obtained with SBIF and serum collected from a single person on multiple occasions, we also investigated the effects on copper-mediated LDL oxidation of SBIF and serum obtained from two additional subjects. The percent inhibition of REM for $1 \%$ serum and SBIF, respectively, were 43 and $27 \%$ for the first subject, and 38 and $33 \%$ for the second subject, i.e., $42.3 \pm 4.3$ and $30.3 \pm 3.4 \%$ for all three subjects (mean $\pm \mathrm{SD}$ ). These data indicate that there is little interindividual variation in the effect of serum and SBIF from healthy individuals on copper-mediated LDL oxidation in vitro.

In the macrophage system both serum and SBIF inhibited LDL oxidation in a dose-dependent manner, as assessed by REM (Fig. $2 A$ ) and TBARS formation (Fig. $2 B$ ). When added at a concentration of $6 \%$ ( vol/vol), both SBIF and serum inhibited macrophage-mediated increases in the electrophoretic mobility of LDL by $>90 \%$ (Fig. $2 A$ ). However, SBIF was significantly less effective than serum at inhibiting LDL oxidation at $1 \%(P<0.05)$ and $0.5 \%(P<0.01)$ (Fig. $2 A)$. From the data in Fig. $2 A$, we calculate that the concentrations required to inhibit macrophage-mediated LDL oxidation by $50 \%\left(\mathrm{IC}_{50}\right)$ are $0.3 \%$ serum and $0.7 \%$ SBIF. To again address the issue of interindividual variation, the effect of $6 \%$ serum or SBIF from two additional subjects on macrophage-mediated LDL oxidation was determined. The percent inhibition of REM for $6 \%$ serum and SBIF, respectively, were 87 and $85 \%$ for the first subject, and 92 and $83 \%$ for the second subject, i.e., $91.7 \pm 4.5$ and $87.3 \pm 5.0 \%$ for all three subjects (mean \pm SD). As above, these data indicate that the results obtained with the first subject are representative of healthy individuals and may be generalized.

In the absence of macrophages, i.e., when LDL was incubated in Ham's F-10 medium containing $10 \mu \mathrm{M}$ Fe-NTA, 6\% SBIF or serum very effectively prevented LDL oxidation (Fig. $3)$. At higher dilutions SBIF was less effective than serum $(P$ $<0.05$ at $1 \%, P<0.01$ at $0.5 \%$, and $P<0.001$ at $0.25 \%$ ) (Fig. 3). The $\mathrm{IC}_{50}$ for iron-mediated LDL oxidation determined 

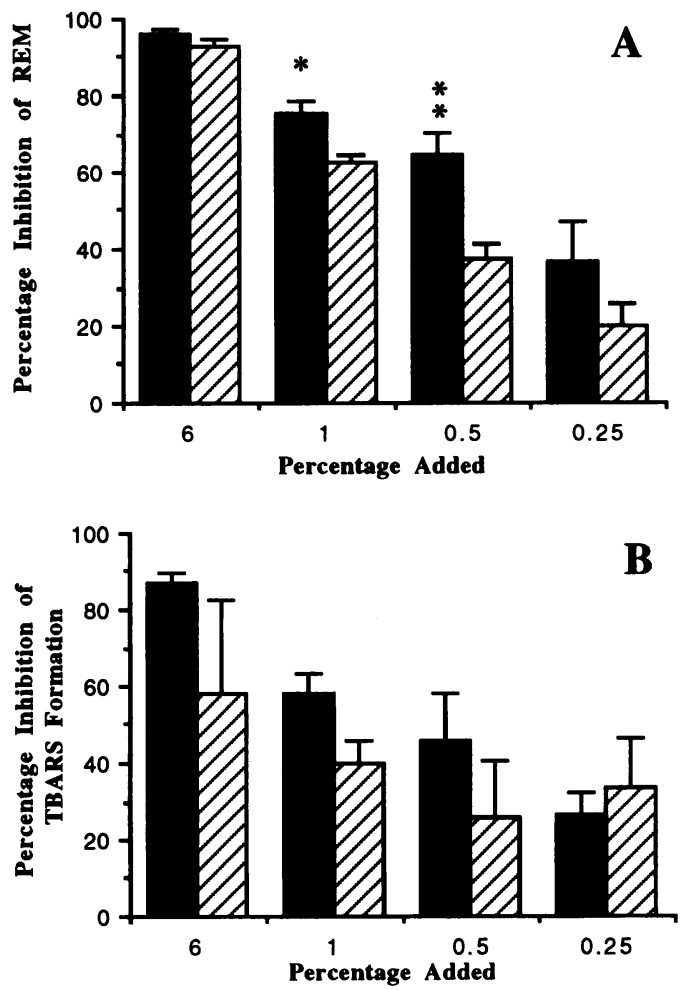

Figure 2. Inhibition of macrophage-mediated LDL oxidation by serum and SBIF. LDL (protein $=100 \mu \mathrm{g} / \mathrm{ml}$ ) was incubated with $1.5 \times 10^{6}$ murine macrophages in $0.5 \mathrm{ml}$ of Ham's F-10 medium containing 10 $\mu \mathrm{M}$ Fe-NTA. Heat-inactivated serum (solid columns) or SBIF (hatched columns) were added at $6,1,0.5$, and $0.25 \%(\mathrm{vol} / \mathrm{vol})$, or no addition was made (control). After $24 \mathrm{~h}$ of incubation at $37^{\circ} \mathrm{C}$ (in a humidified incubator; $5 \% \mathrm{CO}_{2}$ ), the electrophoretic mobility and the TBARS content of LDL were determined. Results are expressed as percent inhibition of REM $(A)$ and TBARS formation $(B)$ compared to control LDL ( $0 \%$ inhibition) and native LDL ( $100 \%$ inhibition), and represent the mean\pm standard error of three to four experiments using serum or SBIF obtained from the same healthy donor on different occasions. Mean $\mathrm{REM} \pm$ standard error for control LDL was $5.7 \pm 0.70, n=4{ }^{*} P<0.05$, and $* * P<0.01$, SBIF vs. serum.

from the data shown in Fig. 3 was $<0.25 \%$ serum and $0.4 \%$ SBIF. Similarly, for the additional two subjects, the $\mathrm{IC}_{50}$ was $<0.25 \%$ serum, and 0.4 and $0.5 \%$ SBIF.

Interestingly, very low concentrations of serum more strongly protected LDL against oxidation in the cell-free system than in the macrophage system $(P<0.01$ at $0.25 \%$ serum $)$ (Figs. $2 A$ and 3). This difference may be due to the milder oxidizing conditions in the iron compared to the macrophage system (mean REM of LDL, \pm standard error, after $24 \mathrm{~h}$ of incubation was $4.9 \pm 0.69$ and $5.7 \pm 0.70$, respectively; $n=4$ ). Furthermore, this difference may indicate different mechanisms of LDL protection by SBIF and serum in the two oxidation systems.

To investigate the role of the aqueous low molecular weight antioxidants urate and ascorbate in the inhibition of LDL oxidation by SBIF and serum, these fluids were incubated with ascorbate oxidase, uricase, or, as a control, without added enzymes. Enzymatic treatment removed all ascorbate and urate ( $>99 \%$ efficiency). The treated samples were then compared for their ability to protect LDL from oxidation. As shown in Table II, both serum and SBIF which had been depleted of either ascor-

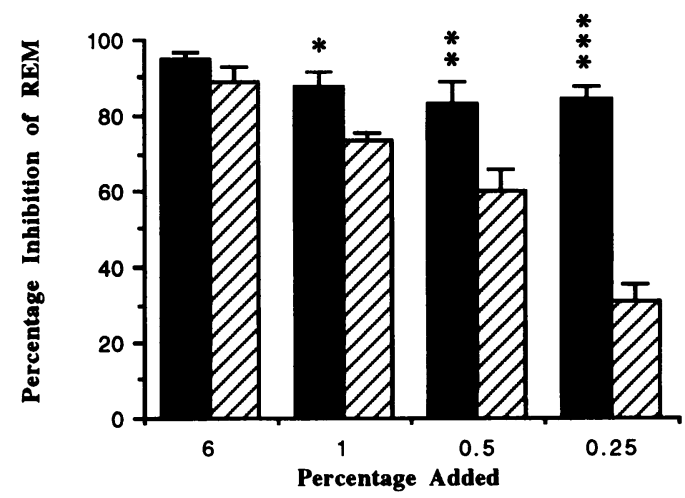

Figure 3. Inhibition of iron-mediated LDL oxidation in a cell-free system by serum and SBIF. LDL (protein $=100 \mu \mathrm{g} / \mathrm{ml}$ ) was incubated in $0.5 \mathrm{ml}$ of Ham's F-10 medium containing $10 \mu \mathrm{M}$ Fe-NTA. Serum ( solid columns) or SBIF (hatched columns) were added at $6,1,0.5$, and $0.25 \%$ ( vol/vol), or no addition was made (control). After $24 \mathrm{~h}$ of incubation at $37^{\circ} \mathrm{C}$ (in a humidified incubator; $5 \% \mathrm{CO}_{2}$ ), the electrophoretic mobility of LDL on an agarose gel was measured. Results are expressed as percent inhibition of REM compared to control LDL ( $0 \%$ inhibition ) and native LDL ( $100 \%$ inhibition), and represent the mean\pm standard error of three to five experiments using serum or SBIF obtained from the same healthy donor on different occasions. Mean $\mathrm{REM} \pm$ standard error for control LDL was $4.9 \pm 0.69, n=4$. $* P<0.05$, $* * P<0.01$, and $* * * P<0.001$, SBIF vs. serum.

bate or urate were as effective as control serum and SBIF at inhibiting LDL oxidation in the macrophage and iron systems.

To investigate the contribution of high molecular weight compounds in serum to its protective effects against LDL oxidation, serum was treated by gel filtration on a Sephadex G25-300 column. This treatment removed low molecular weight

Table II. Effect of Enzymatic Removal of Ascorbate and Urate from Serum and SBIF on Inhibition of Macrophage- and Iron-mediated LDL Oxidation

\begin{tabular}{lll}
\hline & \multicolumn{2}{c}{ Percent inhibition of REM } \\
\cline { 2 - 3 } Addition & Macrophages & Fe-NTA \\
\hline $6 \%$, volvol & & \\
Serum & & \\
$\quad$ Control & $96.3 \pm 2.9(4)$ & $96.0 \pm 3.4(4)$ \\
Ascorbate-free & $95.0 \pm 4.2(3)$ & $98.0 \pm 2.9(3)$ \\
Urate-free & $94.7 \pm 3.1(3)$ & $97.7 \pm 2.5(3)$ \\
SBIF & & \\
Control & $92.8 \pm 4.3(4)$ & $95.6(1)$ \\
Ascorbate-free & $91.0 \pm 6.2(3)$ & $95.6(1)$ \\
Urate-free & $92.7 \pm 6.1(3)$ & $95.0(1)$ \\
\hline
\end{tabular}

LDL (protein $=100 \mu \mathrm{g} / \mathrm{ml}$ ) was incubated in $0.5 \mathrm{ml} \mathrm{Ham}$ 's F-10 medium containing $10 \mu \mathrm{M} \mathrm{Fe}-\mathrm{NTA}$ in the presence or absence of $1.5 \times 10^{6}$ murine macrophages. Control serum and SBIF, ascorbate- and uratefree serum or SBIF were added at $6 \%(\mathrm{vol} / \mathrm{vol})$. After $24 \mathrm{~h}$ of incubation at $37^{\circ} \mathrm{C}$ (in a humidified incubator; $5 \% \mathrm{CO}_{2}$ ), the electrophoretic mobility of LDL on an agarose gel was measured. Results are expressed as percent inhibition of REM (see legend of Fig. 1) and represent the mean $\pm S D$ of three to four experiments (except for SBIF in the Fe-NTA system) using serum or SBIF obtained from the same healthy donor on different occasions (numbers in parentheses). 
Table III. Inhibition of Copper-, Macrophage-, and Iron-mediated LDL Oxidation by Serum, Gel-filtered Serum, and the High and Low Molecular Weight Components of Serum

\begin{tabular}{llcc}
\hline & \multicolumn{3}{c}{ Percent inhibition of REM } \\
\cline { 2 - 4 } \multicolumn{1}{c}{\begin{tabular}{c} 
Serum addition \\
\cline { 2 - 4 } , vol/vol $)$
\end{tabular}} & \multicolumn{1}{c}{$\mathrm{CuSO}_{4}$} & \multicolumn{1}{c}{ Macrophages } & Fe-NTA \\
\hline Control & $89.8 \pm 5.3(4)$ & $82.0 \pm 13.0(3)$ & $95.7 \pm 5.8(3)$ \\
Gel-filtrate & $82.6 \pm 11.2(4)$ & $79.0 \pm 13.4(3)$ & $92.7 \pm 5.1(3)$ \\
Retenate $(>30 \mathrm{kD})$ & $90.0 \pm 5.3(3)$ & $80.2 \pm 7.1(3)$ & $94.0 \pm 8.7(3)$ \\
Filtrate $(<30 \mathrm{kD})$ & $19.9 \pm 9.9(3)^{*}$ & $0.7 \pm 4.6(3)^{*}$ & $17.8 \pm 7.8(3)^{*}$
\end{tabular}

LDL (protein $=100 \mu \mathrm{g} / \mathrm{ml}$ ) was incubated in $0.5 \mathrm{ml}$ of Ham's F-10 medium containing $5 \mu \mathrm{M} \mathrm{CuSO}_{4}$ or $10 \mu \mathrm{M}$ Fe-NTA in the presence or absence of $1.5 \times 10^{6}$ murine macrophages. Control serum or treated samples were added at $6 \%(\mathrm{vol} / \mathrm{vol})$. After $24 \mathrm{~h}$ of incubation at $37^{\circ} \mathrm{C}$ (in a humidified incubator; $5 \% \mathrm{CO}_{2}$ ), the electrophoretic mobility of LDL on an agarose gel was measured. Results are expressed as percent inhibition of REM (see legend of Fig. 1) and represent the mean \pm SD of three to four experiments using serum obtained from the same healthy donor on different occasions (numbers in parentheses). ${ }^{*} P<0.001$ as compared to control. Differences between control samples and gel-filtrate or retenate were all statistically not significant $(P>0.05)$.

compounds such as urate and ascorbate with $>96 \%$ efficiency. The gel filtrate containing the high molecular weight fraction inhibited LDL oxidation almost as effectively as untreated serum in all three oxidation systems (Table III). Similarly, when serum was separated by centrifugation into a low molecular weight filtrate fraction and a high molecular weight $(>30,000$ D) retenate fraction, the latter was very effective at inhibiting LDL oxidation, whereas the low molecular weight filtrate fraction had little or no effect (Table III). Furthermore, lipoprotein deficient plasma protected LDL against oxidation as effectively as control plasma (data not shown). These data strongly suggest that it is the proteins in serum and SBIF that are mediating the inhibitory effect of these fluids against metal ion-dependent LDL oxidation, and not small molecular weight components such as ascorbate and urate, or lipoprotein-associated antioxidants.

To further characterize the protective effect of the retenate fraction, we investigated the role of albumin and transferrin in iron- and copper-mediated LDL oxidation. Both of these proteins are present in the retenate fraction $(\mathrm{mol} \mathrm{wt}>30,000)$ of serum, and have been reported to act as antioxidants $(37,38)$. The concentrations of albumin, the most abundant protein in plasma, and transferrin are $\sim 50$ and $3.5 \%$, respectively, of total plasma proteins. Human albumin at a concentration found in $6 \%$ serum significantly $(P<0.01)$ inhibited copper-mediated LDL oxidation and slightly inhibited iron-mediated LDL oxidation (Fig. 4). Conversely, apo-transferrin slightly inhibited and significantly $(P<0.01)$ inhibited copper- and iron-mediated LDL oxidation, respectively. The inhibitory effect of transferrin was related to the degree of its iron saturation: holo-transferrin ( $100 \%$ iron-saturated) did not inhibit LDL oxidation in both of the above systems, while transferrin saturated to $20-30 \%$ with iron (physiological plasma saturation) had an intermediary effect between holo- and apo-transferrin on iron-mediated LDL oxidation (Fig. 4). These data suggest that the antioxidant activity of transferrin in this system is due to its iron-binding capacity. When albumin and physiologically saturated transferrin

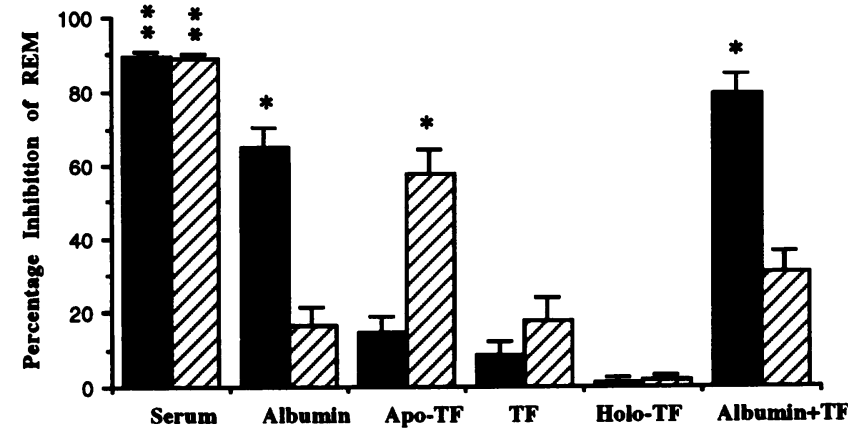

Figure 4. Inhibition of copper- and iron-mediated LDL oxidation by serum, albumin, and transferrin. Albumin and transferrin solutions were made in $0.15 \mathrm{M}$ PBS at average plasma concentrations $(50 \mathrm{mg} / \mathrm{ml}$ and $3 \mathrm{mg} / \mathrm{ml}$, respectively). LDL (protein $=100 \mu \mathrm{g} / \mathrm{ml}$ ) was incubated with $5 \mu \mathrm{M} \mathrm{CuSO}_{4}$ (solid columns) or $10 \mu \mathrm{M}$ Fe-NTA (hatched columns) in Ham's F-10 medium in the absence (control) or presence of $6 \%(\mathrm{vol} / \mathrm{vol})$ of either serum, albumin, apo-transferrin (Apo-TF), transferrin $(T F)$, holo-transferrin (Holo- $T F)$, or a combination of albumin and transferrin. After $24 \mathrm{~h}$ of incubation at $37^{\circ} \mathrm{C}$ (in a humidified incubator; $5 \% \mathrm{CO}_{2}$ ), the electrophoretic mobility of $\mathrm{LDL}$ on an agarose gel was measured. Results are expressed as percent inhibition of REM compared to control LDL ( $0 \%$ inhibition) and native LDL ( $100 \%$ inhibition), and represent the mean \pm standard error of three experiments using serum obtained from the same healthy donor on different occasions. Mean REM \pm standard error for control LDL in the copper- and ironmediated systems were $6.2 \pm 0.56$ and $4.8 \pm 0.26$, respectively. ${ }^{*} P$ $<0.01$, and $* * P<0.001$ as compared to no addition control.

were combined together at concentrations found in $6 \%$ serum, LDL oxidation was inhibited in both metal ion-dependent systems, but only significantly in the copper system $(P<0.01)$. The protective effects of these two proteins were additive and together accounted for $\sim 85$ and $35 \%$ of the serum antioxidant activity in the copper and iron systems, respectively (Fig. 4).

\section{Discussion}

In this study, we compared the antioxidant composition of human plasma to that of SBIF, a model of interstitial fluid, and investigated the differential effects of SBIF and serum on metal ion-dependent oxidative modification of LDL. We found that ascorbate and urate concentrations in SBIF are similar to plasma concentrations. In contrast, the levels of the lipoprotein-associated antioxidants ubiquinol-10, $\alpha$-tocopherol, $\beta$-carotene, and lycopene were low in SBIF compared to plasma $(8-20 \%)$ and closely mirrored the relative concentrations of lipoprotein-associated lipids $(13-23 \%)$. Therefore, the protection of the lipoprotein lipids by the endogenous lipid-soluble antioxidants should be about equal in SBIF and plasma. These are expected findings since the size of a molecule is a major factor in its ability to diffuse from the vasculature into the interstitium (23). For example, it has been shown that the SBIF to plasma concentration ratio for LDL (apo B) and albumin are $\sim 0.16$ and 0.29 , respectively $(21,23)$, which is comparable to the relative distribution of lipids $(0.13-0.23)$ and albumin $(0.27)$ observed in the present study. Thus, in agreement with previous data (21, 23, 26), we observed a "molecular sieve" effect, with large molecules and their associated compounds present at lower concentrations in SBIF than in plasma, and small, free molecules at similar concentrations. 
We also found that the redox status of SBIF and plasma are essentially the same, as assessed by both ascorbate and ubiquinone-10 redox status, and that neither fluid contains detectable amounts of lipid hydroperoxides $(<5 \mathrm{nM})$. To extend these observations to aortic intimal IF relevant to atherosclerosis, the concentrations of low molecular weight antioxidants such as ascorbate and urate should be similar to those in SBIF by virtue of the small size of these compounds and, presumably, their ability to diffuse freely from plasma into the aortic intima. Since LDL levels in the aortic IF are twice as high as in plasma $(19,20)$, the levels of the lipid-soluble antioxidants can be expected to be much higher ( $\sim 10$-fold $)$ in this fluid than in SBIF. However, as explained above, the ratio of LDL to lipidsoluble antioxidants is likely to be similar in both fluids, as well as plasma, because the lipoproteins themselves are the carriers of lipid-soluble antioxidants.

We demonstrated that removal of ascorbate and urate does not affect the ability of serum and SBIF to protect LDL against oxidative modification. This may appear surprising in light of our recent finding that ascorbate very effectively prevents copper-mediated LDL oxidation (39). However, ascorbate only protected above a threshold concentration of 50-60 $\mu \mathrm{M}(39$, 40 ). In the present study ascorbate levels in the LDL oxidation systems were always below $10 \mu \mathrm{M}$, as SBIF and serum were diluted more than 10-fold. Our data further indicate that the lipid-soluble antioxidants in serum and SBIF do not play a significant role in preventing LDL oxidation in our in vitro systems. This is because the concentrations of these lipid-soluble antioxidants in $\geq 10$-fold diluted serum or SBIF were too low to have a measurable effect on LDL oxidation. For example, $10 \%$ SBIF inhibited $\mathrm{Cu}^{2+}$-mediated LDL oxidation by $90 \%$ (Fig. $1 B$ ) and $0.25 \%$ serum inhibited iron-mediated LDL oxidation by $84 \%$ (Fig. 3 ), yet the $\alpha$-tocopherol concentrations present in these amounts of SBIF and serum were $<1.0$ and 0.1 $\mu \mathrm{M}$, respectively. Esterbauer and colleagues have shown that addition of up to $2.5 \mu \mathrm{M} \alpha$-tocopherol does not exert an inhibitory effect on $\mathrm{Cu}^{2+}$-mediated LDL oxidation (41). In addition, the lipid-soluble antioxidants added in serum or SBIF are not free but are themselves integral parts of lipoproteins, i.e., the ratio of lipid-soluble antioxidants to lipoprotein lipids does not change by adding serum or SBIF to an incubation system containing LDL (see above). Finally, we observed that lipoproteindeficient plasma, which was essentially depleted of lipid-soluble antioxidants, was as effective as control plasma in preventing LDL oxidation, in agreement with previous data $(9,42)$. Thus, in our experiments, neither water- nor lipid-soluble small molecular weight antioxidants significantly contributed to the protection of LDL by SBIF or serum. Rather, the protection of LDL resided mainly in the high molecular weight protein fraction of serum. Since all three LDL oxidation systems used in this study were metal ion-dependent (copper, iron, or macrophages in Ham's F-10 medium), the metal-binding proteins of SBIF and serum may play a major role in the ability of these fluids to prevent LDL oxidation.

The antioxidants in serum are known to include proteins that bind metal ions or biological iron complexes in a form that prevents them from participating in free-radical reactions $(37$, 38 ). Transferrin is an iron-transport protein which under physiological conditions is only $20-30 \%$ saturated with iron and hence has the capacity to bind additional, potentially catalytic iron ions (43). We have demonstrated that transferrin at a concentration found in $6 \%$ serum effectively inhibits iron-mediated
LDL oxidation. This effect was related to the degree of iron saturation, indicating that the antioxidant capacity of transferrin is a function of its iron-binding capacity. These findings confirm previous observations on the inhibition of iron-mediated lipid peroxidation by transferrin (44-46). We also observed that transferrin slightly protects LDL against copper-mediated oxidation, which may be due to its ability to weakly bind copper (47).

Another important metal-binding protein in plasma is ceruloplasmin. In addition to binding copper, ceruloplasmin can catalyze the oxidation of ferrous to ferric iron. This so-called ferrioxidase activity of ceruloplasmin inhibits iron-stimulated lipid peroxidation and hydroxyl radical production by the Fenton reaction (48) and promotes the incorporation of iron into transferrin (49) and the iron-storage protein ferritin (50). However, recent data (51) indicate that the ceruloplasmin used in in vitro studies $(48)$ is a degraded form obtained from commercial suppliers. Surprisingly, highly purified human ceruloplasmin acts as an oxidant supporting, rather than inhibiting, coppermediated LDL oxidation (51). However, very low concentrations of albumin $(2.5 \mathrm{mg} / \mathrm{dl})$ significantly inhibit LDL oxidation mediated by ceruloplasmin (51). Hence, in the context of the present study, ceruloplasmin is not likely to cause LDL oxidation, as we have demonstrated that SBIF contains $\sim 1.2$ $\mathrm{g} / \mathrm{dl}$ of albumin. Even in incubations where $0.25 \% \mathrm{SBIF}$ was used, albumin levels $(3 \mathrm{mg} / \mathrm{dl})$ exceeded those required to inhibit the oxidative ability of ceruloplasmin. Furthermore, ceruloplasmin is more likely to act as an antioxidant in our ironmediated systems by virtue of its ferrioxidase activity $(48,49)$.

Albumin, which binds copper tightly and iron weakly, also contributes to the antioxidant defenses in plasma $(37,38)$. We have demonstrated that albumin markedly inhibits copper-mediated LDL oxidation, contributing $\sim 85 \%$ to the total antioxidant effect of serum. This is in agreement with other studies on copper-mediated LDL oxidation $(51,52)$. In contrast to the copper system, albumin only slightly inhibited iron-mediated LDL oxidation (Fig. 4), in keeping with the known weak ironbinding capacity of albumin (37). Other investigators have also reported that albumin provides either no (46) or little (45) antioxidant protection against iron-mediated lipid peroxidation.

Therefore, our, as well as published, data (44-46) suggest that metal-binding proteins in serum and SBIF, such as albumin and transferrin, play an important role in preventing metal iondependent oxidative modification of LDL. However, the question arises as to whether the known antioxidant proteins in serum and SBIF account for $100 \%$ of the protective effects of these fluids in the oxidation systems used in the present study. The levels of the antioxidant proteins in plasma have been well characterized (37). Even though we have not measured antioxidant proteins in SBIF (except for albumin), other investigators have done so $(21,23)$ or have estimated their levels based on molecular weight and diffusion coefficients (26). For example, the SBIF to plasma concentration ratios for ceruloplasmin and transferrin have been estimated at 0.28 and 0.40 , respectively $(23,26)$. In view of the much lower levels of antioxidant proteins in SBIF compared to serum, one might expect SBIF to be drastically less effective than serum in protecting LDL from oxidative modification. However, we found that serum and, only to a somewhat lesser degree, SBIF are highly protective of LDL in all three metal ion-dependent oxidation systems investigated in this study. Even when diluted more than 10-fold, serum and SBIF inhibited LDL oxidation very 
effectively. The $\mathrm{IC}_{50}$ for macrophage-mediated LDL oxidation was as low as $0.3 \%$ ( $\mathrm{vol} / \mathrm{vol}$ ) serum and $0.7 \%$ SBIF, and was even lower for iron-mediated LDL oxidation, $<0.25 \%$ serum and $0.4 \%$ SBIF. The $\mathrm{IC}_{50}$ for serum against macrophage-mediated and cell-free LDL oxidation has been previously estimated at $\sim 1(9)$ and $0.25 \%(42)$, respectively.

Interestingly, the copper-binding capacity of serum is $\sim 250$ $\mu \mathrm{M}$ (53), and copper-mediated LDL oxidation in whole plasma (as assessed by REM) only occurs at copper concentrations $>250 \mu \mathrm{M}$ (54). In the present study, we used $5 \mu \mathrm{M} \mathrm{CuSO}_{4}$ and observed almost complete inhibition of LDL oxidation by $10 \%$ serum (corresponding to $\sim 25 \mu \mathrm{M}$ copper-binding capacity), and only partial inhibition by $1 \%$ serum $(\sim 2.5 \mu \mathrm{M}$ copper-binding capacity). Importantly, similar results were obtained with SBIF (Fig. 1). As mentioned above, one would expect considerably less protection with SBIF than with serum, given the large differences in albumin and protein levels between these fluids. Our data, therefore, suggest that the protective effect of serum and SBIF is not due to a single or a few known copper-binding proteins but may be due to a cumulative effect of many proteins that can bind metal ions (55). This conception is further supported by the observation that several unrelated proteins (e.g., albumin, collagen, and gelatin), can inhibit copper-mediated LDL oxidation at very low concentrations (51).

As in copper-binding to plasma proteins, it has been demonstrated that iron is distributed over plasma proteins in addition to transferrin if the latter is $>50 \%$ iron-saturated $(56)$. Therefore, it is likely that in the iron-dependent LDL oxidation systems used in the present study (iron or macrophages) several serum proteins contributed to iron-binding and, thus, inhibition of LDL oxidation. Furthermore, since both SBIF and serum strongly protected even at very high dilutions, the concentration of any single protein is probably too low to have a substantial protective effect by itself. This supports the conception that the protective effect is due to a cumulative effect of many plasma and SBIF proteins.

In conclusion, our data show that human SBIF is highly efficient at preventing metal ion-dependent LDL oxidation in vitro. This raises the anticipated and persistent question of the mechanism and location of LDL oxidation in vivo. If the IF in the intimal subendothelial space is similar to the model of IF used in this study, it appears highly unlikely that LDL gets modified in the arterial wall by metal ion-catalyzed oxidation. If LDL gets oxidized in vivo by a metal ion-independent mechanism, antioxidants other than metal-binding proteins in aortic intimal IF may play a significant protective role. For example, it has been suggested that LDL is modified by myeloperoxidasederived hypochlorous acid $(57,58)$. Under these oxidizing conditions, ascorbate and albumin thiols $(16,59)$ would be the primary antioxidants in IF. It may also be that LDL oxidation in vivo occurs in a microenvironment close to the cells, which is not accessible to the protective constituents of IF. Such questions are crucial to the understanding of the atherosclerotic process and the intervention or treatment of the disease.

\section{Acknowledgments}

We thank Emily Cheh and Timi Mannion for excellent technical assistance.

Financial support for this work was provided by grant $13-528-901$ from the American Heart Association, Massachusetts Affiliate, Inc., and grant 3412 from the Council for Tobacco Research-U.S.A., Inc.

\section{References}

1. Steinberg, D., S. Parthasarathy, T. E. Carew, J. C. Khoo, and J. L. Witztum. 1989. Beyond cholesterol. Modifications of low-density lipoprotein that increase its atherogenecity. N. Engl. J. Med. 320:915-924.

2. Schwartz, C. J., A. J. Valente, E. A. Sprague, J. L. Kelley, and R. M. Nerem. 1991. The pathogenesis of atherosclerosis: an overview. Clin. Cardiol. 14:I1-I16.

3. Goldstein, J. L., Y. K. Ho, S. K. Basu, and M. S. Brown. 1979. Binding sites on macrophages that mediate uptake and degradation of acetylated low density lipoprotein, producing massive cholesterol deposition. Proc. Natl. Acad. Sci. USA. 76:333-337.

4. Galle, J., A. Mülsch, R. Busse, and E. Bassenge. 1991. Effects of native and oxidized low density lipoprotein on formation and inactivation of endothelium-derived relaxing factor. Arterioscler. Thromb. 11:198-203.

5. Tanner, F. C., G. Noll, C. M. Boulanger, and T. F. Lüscher. 1991. Oxidized low density lipoproteins inhibit relaxations of porcine coronary arteries. Role of scavenger receptor and endothelium-derived nitric oxide. Circulation. 83:20122020.

6. Steinbrecher, U. P., S. Parthasarathy, D. S. Leake, J. L. Witztum, and D. Steinberg. 1984. Modification of low density lipoprotein by endothelial cells involves lipid peroxidation and degradation of low density lipoprotein phospholipids. Proc. Natl. Acad. Sci. USA. 81:3883-3887.

7. Heinecke, J. W., H. Rosen, and A. Chait. 1984. Iron and copper promote modification of low density lipoprotein by human arterial smooth muscle cells in culture. J. Clin. Invest. 74:1890-1894.

8. Parthasarathy, S., D. J. Printz, D. Boyd, L. Joy, and D. Steinberg. 1986. Macrophage oxidation of low density lipoprotein generates a modified form recognized by the scavenger receptor. Arteriosclerosis. 6:505-510.

9. Leake, D. S., and S. M. Rankin. 1990. The oxidative modification of lowdensity lipoproteins by macrophages. Biochem. J. 270:741-748.

10. Daugherty, A., B. S. Zweifel, B. E. Soble, and G. Schonfeld. 1988 Isolation of low density lipoprotein from atherosclerotic vascular tissue of Watanabe heritable hyperlipidemic rabbits. Arteriosclerosis. 8:768-777.

11. Ylä-Herttuala, S., W. Palinski, M. E. Rosenfeld, S. Parthasarathy, T. E. Carew, S. Butler, J. L. Witztum, and D. Steinberg. 1989. Evidence for the presence of oxidatively modified low density lipoprotein in atherosclerotic lesions of rabbit and man. J. Clin. Invest. 84:1086-1095.

12. Steinbrecher, U. P., and M. Lougheed. 1992. Scavenger receptor-independent stimulation of cholesterol esterification in macrophages by low density lipoprotein extracted from human aortic intima. Arterioscler. Thromb. 12:608-625.

13. Palinski, W., M. E. Rosenfeld, S. Ylä-Herttuala, G. C. Gurtner, S. S. Socher, S. W. Butler, S. Parthasarathy, T. E. Carew, and D. Steinberg. 1989. Low density lipoprotein undergoes oxidative modification in vivo. Proc. Natl. Acad. Sci. USA. 86:1372-1376.

14. Avogaro, P., G. B. Bon, and G. Cazzolato. 1988. Presence of a modified low density lipoprotein in humans. Arteriosclerosis. 8:79-87.

15. Hodis, H. N., D. M. Kramsch, P. Avogaro, G. Bittolo-Bon, G. Cazzolato, J. Hwang, H. Peterson, and A. Sevanian. 1994. Biochemical and cytotoxic characteristics of an in vivo circulating oxidized low density lipoprotein (LDL-). J. Lipid Res. 35:669-677.

16. Frei, B., R. Stocker, and B. N. Ames. 1988. Antioxidant defenses and lipid peroxidation in human blood plasma. Proc. Natl. Acad. Sci. USA. 85:97489752.

17. Frei, B., Y. Yamamoto, D. Niclas, and B. N. Ames. 1988. Evaluation of an isoluminol chemiluminescence assay for the detection of hydroperoxides in human blood plasma. Anal. Biochem. 175:120-130.

18. Sloop, C. H., L. Dory, and P. S. Roheim. 1987. Interstitial fluid lipoproteins. J. Lipid Res. 28:225-237.

19. Smith, E. B., and E. M. Staples. 1980. Distribution of plasma proteins across the human aortic wall. Barrier functions of endothelium and internal elastic lamina. Atherosclerosis. 37:579-590.

20. Smith, E. B., and E. M. Staples. 1982. Plasma protein concentrations in interstitial fluid from human aortas. Proc. R. Soc. London Ser. B Biol. Sci. 217:5975 .

21. Vessby, B., S. Gustafson, M. J. Chapman, K. Hellsing, and H. Lithell. 1987. Lipoprotein composition of human suction-blister interstitial fluid. J. Lipid Res. 28:629-641.

22. Kiistala, U. 1968. Suction blister device for separation of viable epidermis from dermis. J. Invest. Dermatol. 50:129-137.

23. Vermeer, B. J., F. C. Reman, and C. M. Van Gent. 1979. The determination of lipids and proteins in suction blister fluid. J. Invest. Dermatol. 73:303-305.

24. Hoff, H. F., J. W. Gaubatz, and A. M. Gotto. 1978. Apo B concentration in the normal human aorta. Biochem. Biophys. Res. Commun. 85:1424-1430.

25. Camejo, J. 1982. The interactions of lipids and lipoproteins with the 
extracellular matrix of arterial tissue: its possible role in atherogenesis. Adv. Lipid Res. 19:1-53.

26. Volden, G., A. K. Thorsrud, I. Bjørnson, and E. Jellum. 1980. Biochemical composition of suction blister fluid determined by high resolution multicomponent analysis (capillary gas chromatography-mass spectrometry and two-dimensional electrophoresis). J. Invest. Dermatol. 75:421-424.

27. Teichmann, R., and W. Stremmel. 1990. Iron uptake by human upper small intestine microvillous membrane vesicles. Indication for a facilitated transport mechanism mediated by a membrane iron-binding protein. J. Clin. Invest. $86: 2145-2153$

28. Chung, B. H., J. P. Segrest, M. J. Ray, J. D. Brunzell, J. E. Hokanson, R. M. Krauss, K. Beaudrie, and J. T. Cone. 1984. Single vertical spin density gradient ultracentrifugation. Methods Enzymol. 128:181-209.

29. Peterson, G. L. 1977. A simplification of the protein assay method of Lowry et al. which is more generally applicable. Anal. Biochem. 83:346-356.

30. Lowry, O. H., A. L. Rosenbrough, A. L. Farr, and R. J. Randall. 1951. Protein measurement with the Folin phenol reagent. J. Biol. Chem. 193:265-275.

31. Yamamoto, Y., B. Frei, and B. N. Ames. 1990. Assay of lipid hydroperoxides using high-performance liquid chromatography with isoluminol chemiluminescence detection. Methods Enzymol. 186:371-380.

32. Frei, B., L. England, and B. N. Ames. 1989. Ascorbate is an outstanding antioxidant in human blood plasma. Proc. Natl. Acad. Sci. USA. 86:6377-6381.

33. Stocker, R., V. W. Bowry, and B. Frei. 1991. Ubiquinol-10 protects human low density lipoprotein more efficiently against lipid peroxidation than does $\alpha$ tocopherol. Proc. Natl. Acad. Sci. USA. 88:1646-1650.

34. Gutteridge, J. M. C. 1981. Thiobarbituric acid-reactivity following irondependent free-radical damage to amino acids and carbohydrates. FEBS Lett. 128:343-346.

35. Halliwell, B., and J. M. C. Gutteridge. 1981. Formation of a thiobarbituric acid-reactive substance from deoxyribose in the presence of iron salts. FEBS Lett. 128:347-352.

36. Noble, R. P. 1968. Electrophoretic separation of plasma lipoproteins in agarose gel. J. Lipid Res. 9:693-700.

37. Stocker, R., and B. Frei. 1991. Endogenous antioxidant defenses in human blood plasma. In Oxidative Stress: Oxidants and Antioxidants. H. Sies, editor. Academic Press Limited, London. 213-243.

38. Halliwell, B., and J. M. C. Gutteridge. 1990. The antioxidants of human extracellular fluids. Arch. Biochem. Biophys. 280:1-8.

39. Retsky, K. L., M. W. Freeman, and B. Frei. 1993. Ascorbic acid oxidation product(s) protect human low density lipoprotein against atherogenic modification. Anti-rather than prooxidant activity of vitamin $\mathrm{C}$ in the presence of transition metal ions. J. Biol. Chem. 268:1304-1309.

40. Jialal, I., G. L. Vega, and S. M. Grundy. 1990. Physiologic levels of ascorbate inhibit the oxidative modification of low density lipoprotein. Atheroscle rosis. 82:185-191.

41. Esterbauer, H., M. Dieber-Rotheneder, G. Striegl, and G. Waeg. 1991 Role of vitamin $\mathrm{E}$ in preventing the oxidation of low-density lipoprotein. Am. J. Clin. Nutr. 53:314S-321S.

42. Kalant, N., and S. McCormick. 1992. Inhibition by serum components of oxidation and collagen-binding of low density lipoprotein. Biochim. Biophys. Acta. 1128:211-219.

43. Aisen, P. 1970. The physics and physiology of transferrin. Mt. Sinai J. Med. 3:213-222.

44. Stocks, J., J. M. C. Gutteridge, R. J. Sharp, and T. L. Dormandy. 1974. The inhibition of lipid autooxidation by human serum and its relation to serum proteins and $\alpha$-tocopherol. Clin. Sci. Mol. Med. 47:223-233.

45. Gutteridge, J. M. C., and G. J. Quinlan. 1992. Antioxidant protection against organic oxygen radicals by normal human plasma: the important primary role for iron-binding and iron-oxidizing proteins. Biochim. Biophys. Acta. 1159:248-254.

46. Pacht, E. R., and W. B. Davis. 1988. Role of transferrin and ceruloplasmin in antioxidant activity of lung epithelial lining fluid. J. Appl. Physiol. 64:20922099.

47. Aasa, R., and P. Aisen. 1968. An electron paramagnetic resonance study of iron and copper complexes of transferrin. J. Biol. Chem. 243:2399-2404.

48. Gutteridge, J. M. C. 1985. Inhibition of the Fenton reaction by the protein ceruloplasmin and other copper complexes. Assessment of ferrioxidase and radical scavenging activities. Chem. Biol. Interactions. 56:113-120.

49. Osaki, S., D. A. Johnson, and E. Frieden. 1966. The possible significance of the ferrous oxidase activity of ceruloplasmin in normal human serum. J. Biol. Chem. 241:2746-2751.

50. Boyer, R. F., and B. E. Schori. 1983. The incorporation of iron into apoferritin as mediated by ceruloplasmin. Biochem. Biophys. Res. Commun. 116:244-250.

51. Ehrenwald, E., G. M. Chisolm, and P. L. Fox. 1994. Intact human ceruloplasmin oxidatively modifies low density lipoprotein. J. Clin. Invest. 93:14931501

52. Thomas, C. E. 1992. The influence of medium components on $\mathrm{Cu}^{2+}$ dependent oxidation of low density lipoproteins and its sensitivity to superoxide dismutase. Biochim. Biophys. Acta. 1128:50-57.

53. Dasgupta, A., and T. Zdunek. 1992. In vitro lipid peroxidation of human serum catalyzed by cupric ion: antioxidant rather than prooxidant role of ascorbate. Life Sci. 50:875-882.

54. Zwadzki, Z., R. W. Milne, and Y. L. Marcel. 1991. Copper-mediated oxidation of dialyzed plasma: effects on low and high density lipoproteins and cholesteryl ester transferase protein. J. Lipid. Res. 32:243-250.

55. Stadtman, E. R., and C. N. Oliver. 1991. Metal-catalyzed oxidation of proteins. Physiological consequences. J. Biol. Chem. 266:2005-2008.

56. Van Der Heul, C., H. G. Van Eijk, W. F. Wiltink, and B. Leijnse. 1972 The binding of iron to transferrin and other serum components at different degree of saturation with iron. Clin. Chim. Acta. 38:347-353.

57. Hazell, L. J., and R. Stocker. 1993. Oxidation of low-density lipoprotein with hypochlorite causes transformation of the lipoprotein into a high-uptake form for macrophages. Biochem. J. 290:165-172.

58. Daugherty, A., J. L. Dunn, D. L. Rateri, and J. W. Heinecke. 1994 Myeloperoxidase, a catalyst for lipoprotein oxidation, is expressed in human atherosclerotic lesions. J. Clin. Invest. 94:437-444.

59. Hu, M. L., S. Louie, C. E. Cross, P. Motchnik, and B. Halliwell. 1993. Antioxidant protection against hypochlorous acid in human plasma. J. Lab. Clin. Med. 121:257-262. 